\title{
Oxygen-Enriched Combustion and the Generation of Nitrogen Oxides in the Ceramic-Sintering Kilns
}

\author{
Satoshi SHIMIZU, Mitsuru WAKAMATSU, Nobuyuki TAKEUCHI, Yoichi HACHITANI \\ and Shoji SHIMIZU* \\ ( Department of Inorganic Materials, Faculty of Engineering and Design, Kyoto Institute of Technology, \\ * Osaka gas Co., Ltd., 5-1, Hirano-machi, Higashi-ku, Osaka-shi 540
}

\section{セラミックス焼結炉における酸素富化燃焼と 窒素酸化物の生成}

\author{
清水 聰. 若松 盈 - 竹内信行 - 蜂谷洋一・清水昭史* \\ 京都工芸繊維大学工芸学部無機材料工学科, 606 京都市左京区松ケ崎御所海道町
$*$ 大阪ガス
}

\begin{abstract}
Oxygen-enriched air was supplied as the combustion air for two combustion-type experimental kilns in order to determine the effect of combustion conditions on the combustion characteristics, particularly the generation of nitrogen oxides. Calculations of the adiabatic equilibrium flame temperature and equilibrium NO concentration for a given air ratio indicated that as the oxygen content in the combustion air increases, both the temperature of the combustion gas and the equilibrium NO concentration increase. Similar calculations for a fixed temperature revealed that the effect of $\mathrm{O}_{2}$ concentration is relatively small and that the $N O$ emissions calculated as an absolute amount per unit of fuel consumed should decline. However, when enriched air was supplied to an experimental kiln, the concentration of NO in the exhaust gas, converted to a percentage of the equilibrium NO concentration at the maximum temperature recorded in the kiln, attained a relatively high value. It was thought that this increase in the NO concentration results from an increase in the combustion reaction rate when enriched air was used in place of ordinary air at a constant air ratio. Furthermore, the data indicated that the effect of the residence time of the combustion gas in the kiln on the concentration of NO, which is relatively unreactive, was significant. When the kiln temperature and air ratio were held at almost the same conditions, a decrease in the fuel gas flow rate produced an increase in the NO value. Oxygen-enriched air may be used in the firing of fine ceramics to attain extremely high kiln temperatures with energy savings.
\end{abstract}

[Received February 8, 1988 ; Accepted June 24, 1988]

Key-words : Oxygen-enriched combustion, Nitrogen oxide, High temperature kiln, Adiabatic flame temperature, Firing of fine ceramics

\section{Introduction}

During the firing of engineering ceramics it is frequently necessary to use high temperatures with strict control of the atmosphere in the kiln. For this operation, at present various radiant heat transfer-type electric furnaces are used almost exclusively. However, when considering for energy conservation and mass production, it would be desirable to develop a combustion-type high temperature furnace in which both temperature and firing atmosphere may be easily controlled.

As a means of obtaining a high temperature in a combustion-type kiln, it is possible to utilize preheated air or to utilize oxygen-enriched air. ${ }^{1,21}$ As examples of the latter, one may cite the Pressure Swing Adsorption (PSA) method, ${ }^{31}$ using molecular sieves, and several methods for blending high-purity oxygen into the combustion air. However, in recent years, oxygen enrichment membrane systems, ${ }^{4}$ which require relatively little input energy for the production of oxygen and which may be used to produce air containing up to $30 \%$ oxygen, have drawn increasing attention. Furthermore, in high temperature combustion, with any of the previously mentioned methods, the generation of nitrogen oxides, compounds which are air pollutants, becomes a problem.

In the present research, the combustion characteristics using oxygen-enriched air were compared with those using ordinary air by operating two different experimental furnaces. In particular, the effects of the degree of oxygen enrichment, the air ratio, and the residence time in the furnace upon the amount of nitrogen oxides produced were investigated. 


\section{Experimental procedure}

The horizontal furnace used in experiments carried out at temperatures up to $1600^{\circ} \mathrm{C}$ is shown schematically in Fig. 1. This furnace contains a combustion chamber with a cross sectional area of $25 \times 25 \mathrm{~cm}^{2}$ and a length of $270 \mathrm{~cm}$. The furnace walls are lined with alumina fibers, and sampling holes are located at three different levels along the side walls. It is thus possible to carry out gas analysis and measure the furnace temperature at each such location. The front of the furnace is equipped with a premixing-type burner, to which the combustion air is supplied in two stages. The burner has been detailed in the previous paper. ${ }^{5)}$

The vertical cylinder-type high temperature furnace shown in Fig. 2 was used for experiments carried out at temperatures above $1750^{\circ} \mathrm{C}$. The furnace has an internal diameter of $30.5 \mathrm{~cm}$ and a length of $54 \mathrm{~cm}$. The inner wall is lined with insulating refractory bricks made of high purity alumina. The burner for this furnace is a double vertical cylinder, diffusion-type burner. Air or oxygen-enriched air is supplied through the inner cylinder and fuel gas is supplied through the outer cylinder. The burner is located tangential to the upper position of the cylindrical combustion chamber. The exhaust gas passes through a vertical cylinder-type metal heat exchanger and is discharged from the unit. The combustion air, which is supplied parallel to the exhaust gas, can be preheated to a maximum temperature of $500^{\circ} \mathrm{C}$.

The fuel used in these experiments was natural gas, composed of $88 \% \mathrm{CH}_{4}, 6 \% \mathrm{C}_{2} \mathrm{H}_{6}, 4 \% \mathrm{C}_{3} \mathrm{H}_{8}$, and $2 \% \mathrm{C}_{4} \mathrm{H}_{10}$. The flow rates for both fuel gas and air were measured with rotameters. Oxygenenriched air was obtained by the use of an enrichment system that employed a silicone membrane. The dissolution rate of oxygen in this silicone membrane is at least twice that of nitrogen. Thus, the concentration of oxygen in the air that is passed through the membrane can be increased. This oxygen enrichment system has
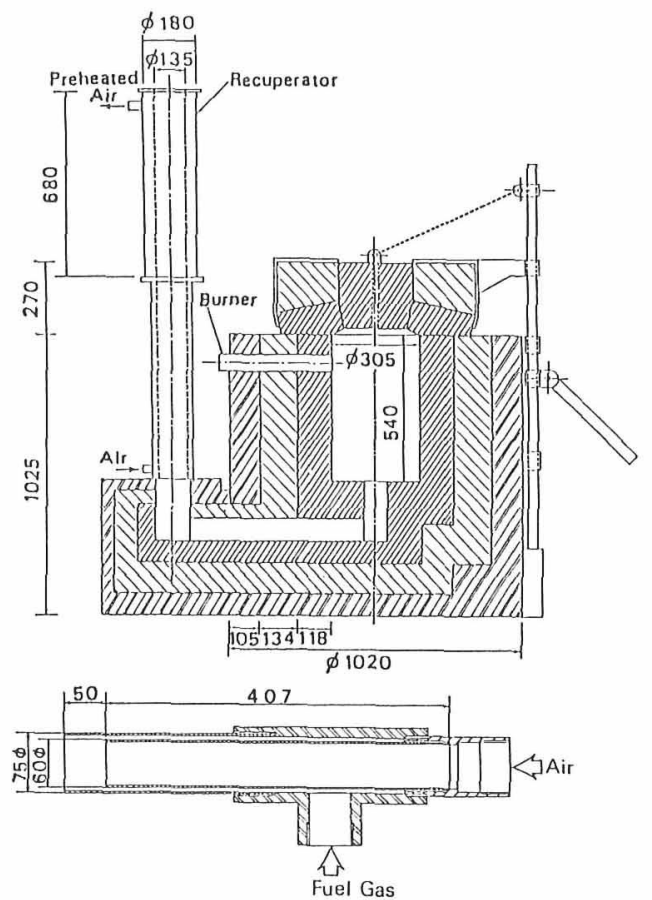

Fig. 2. High temperature vertical kiln and the diffusion-type burner.

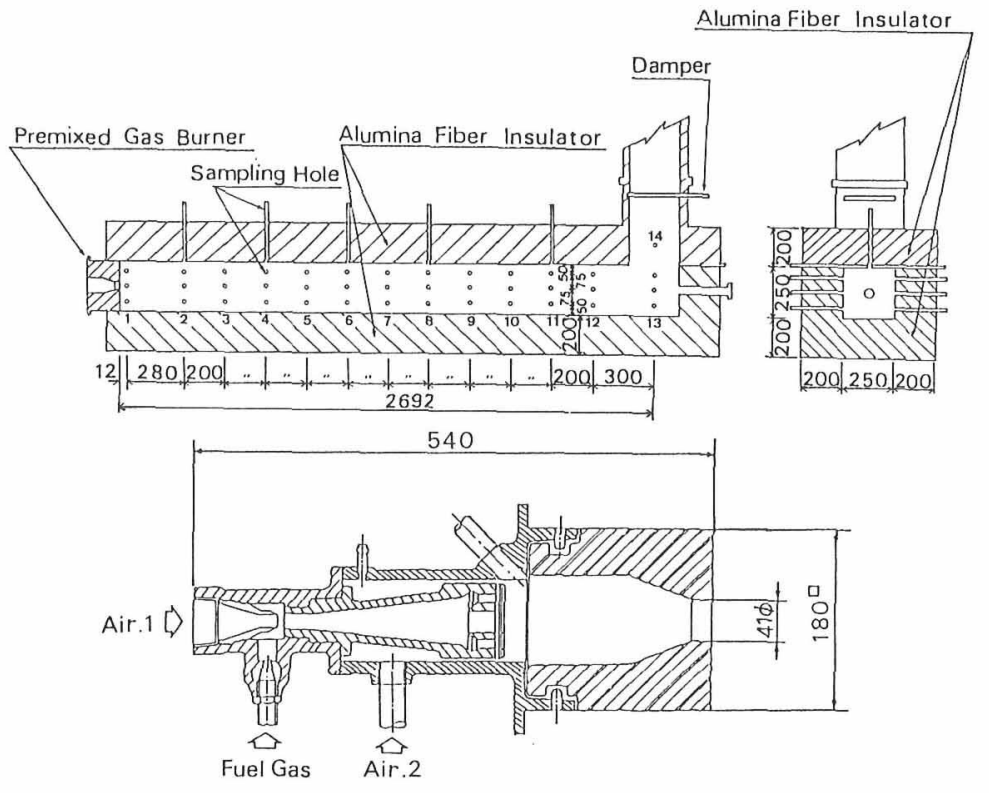

Fig. 1. Horizontal kiln and the premixing-type burner. 
Table 1. Experimental conditions.

\begin{tabular}{|l|c|c|}
\hline & Horizontal kiln & High Temp. Kiln \\
\hline Max. Fuel Rate $\left(\mathrm{m}_{N}^{3} / \mathrm{h}\right)$ & $1.7-2.8$ & $3.8-9.2$ \\
Air Ratio $(-)$ & $1.02-1.20$ & $0.94-1.25$ \\
Max. Temperature $\left({ }^{\circ} \mathrm{C}\right)$ & $1400-1620$ & $1700-1800$ \\
Max. Air Temp. $\left({ }^{\circ} \mathrm{C}\right)$ & - & $455-505$ \\
Enriched $\mathrm{O}_{2}(\mathrm{f})$ & $24.5-25.8$ & $22.8-25.0$ \\
\hline
\end{tabular}

been described in detail in the previous paper. ${ }^{4)}$ The system may produce a maximum oxygen concentration of $30 \%$ and a maximum flow rate of $40 \mathrm{~m}^{3} / \mathrm{h}$, but in these experiments the oxygen concentration of the enriched air was held within the range $23-26 \%$.

The combustion condition for experiments using the horizontal kiln and for those using the high temperature kiln are shown in Table 1. The combustion gas was analyzed for six components : $\mathrm{CO}_{2}, \mathrm{CO}, \mathrm{O}_{2}, \mathrm{H}_{2}, \mathrm{NO}$, and $\mathrm{NO}_{2}$. Temperature measurements were made with a $\mathrm{Pt}-\mathrm{PtRh}$ thermocouple and with a radiation pyrometer.

\section{Results and discussion}

\subsection{Equilibrium concentration for oxygen-} enriched combustion

The effect of oxygen-enriched air on the adiabatic flame temperature of the combustion gas and on the $\mathrm{NO}_{x}$ concentration in equilibrium conditions was first considered. The calculations of the equilibrium concentrations were carried out using well established methods ${ }^{5,6)}$ that employ equilibrium relations and mass balance equations. The adiabatic equilibrium flame temperature was obtained from calculations using an enthalpy balance for the reactants and products at equilibrium conditions. In these calculations, the composition of natural gas was employed as the fuel gas, and the air ratio was varied between 0.8 and 1.5 at the three kinds of the oxygen concentration in the combustion air.

The results of calculations for the adiabatic flame temperature and the corresponding NO concentration, assuming that the fuel is natural gas and that the combustion air is supplied at $25^{\circ} \mathrm{C}$, are shown in Fig. 3. The maximum value for the adiabatic equilibrium flame temperature was not obtained with an air ratio of 1.0 , but the maximum was shifted slightly in the direction of excess fuel. Furthermore, the flame temperature increased with the degree of enrichment in the combustion air. For example, with an air ratio of 1.1 , the flame temperature increased from $1867^{\circ}$ to $2049^{\circ} \mathrm{C}$ if enriched air containing $25 \%$ oxygen was substituted for ordinary air. To obtain this $182^{\circ} \mathrm{C}$ increase in flame temperature using ordinary air, calculations indicate that it would be necessary to preheat the air to approximately

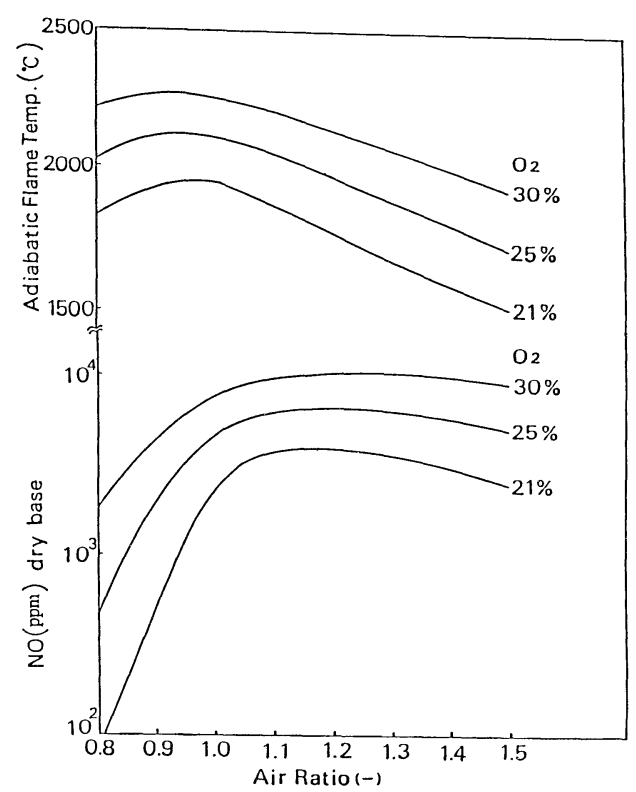

Fig. 3. Adiabatic flame temperature and NO equilibrium concentration.

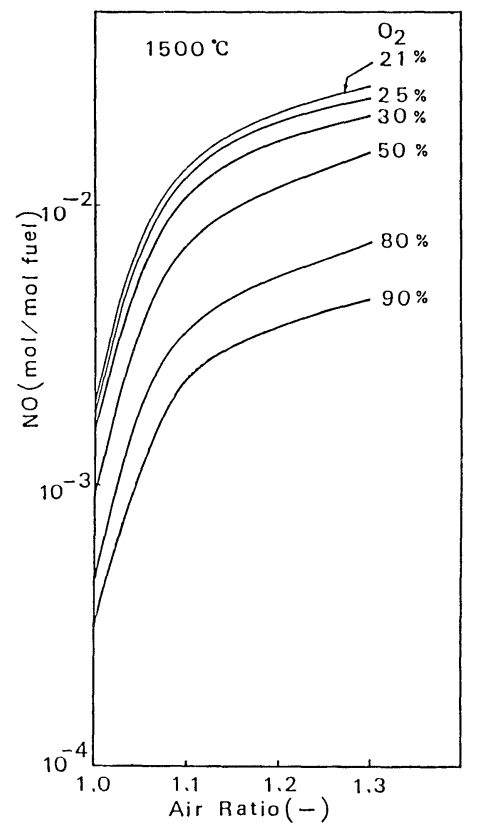

Fig. 4. Effect of oxygen enrichment on NO equilibrium concentration.

$400^{\circ} \mathrm{C}$. The equilibrium concentration of $\mathrm{NO}$ generaly increases with the degree of oxygen enrichment. This increase is attributed in part to the rise in flame temperature and in part to the decrease in amount of combustion gas owing to decrease of nitrogen. The NO concentration may generally decreases after passing through a maximum value as the air ratio increases. This 
decrease results from a decrease in the flame temperature and from a dilution effect with excess air.

Figure 4 indicates the relation between the equilibrium concentration of $\mathrm{NO}$ and the degree of oxygen enrichment assuming a constant temperature of $1500^{\circ} \mathrm{C}$. This value of $1500^{\circ} \mathrm{C}$ was employed by assuming that the combustion gas temperature was lowered by heat lost of furnace walls since, as shown Fig. 3, the adiabatic flame temperature was higher than $1500^{\circ} \mathrm{C}$ in the air ratio range of 0.8 to 1.5 . The concentration of NO in the combustion gas increased with the concentration of oxygen in the combustion air and attained a maximum value at an oxygen concentration of $50 \%$. A further increase in the oxygen concentration lead to a decrease in the NO concentration, as a result of the lower partial pressure of nitrogen in the combustion air. It should be noted that the value for the NO concentration with $25 \%$ oxygen is only about $8.4 \%$ above the value obtained with ordinary air. This increase is due to the decrease in the flow rate of the combustion gas as the degree of enrichment of the combustion air increased. Thus, the amount of NO discharged per unit amount of fuel consumed actually decreased as shown in Fig. 5. This discussion is based completely on equilibrium arguments ; the reaction rate must also be considered in practical applications.

\subsection{The effect of oxygen enrichment on the concentration and distribution of $\mathrm{NO}$ in a horizontal kiln equipped with a premixing burner}

The changes in temperature and in the NO concentration along the kiln axis at the same constant fuel consumption $\left(2.7 \mathrm{~m}^{3} / \mathrm{h}\right)$ and the fixed air ratio (1.15) using ordinary air $\left(\mathrm{O}_{2}\right.$; $21 \%)$ and enriched air $\left(\mathrm{O}_{2} ; 25 \%\right)$ are shown in Fig. 6. All measurements were made after the kiln had reached a steady state. The maximum temperature attained in the kiln was higher and the location where this maximum temperature was recorded shifted closer to the kiln inlet, i. e., short flame, when the ratio of primary air to secondary air was increased from 1.0 (solid line) to 5.8 (broken line). Except for the entry region, the NO concentration profile along the kiln axis was essentially unchanged. An increase in the oxygen concentration from $21 \%$ (solid line) to $25 \%$ (dot dashed line) without changing other parameters caused the maximum temperature to increase by about $105^{\circ} \mathrm{C}$ and led to an increase in the NO concentration from 120 to $470 \mathrm{ppm}$ at the exit of the kiln, i.e., nearly fourfold increase.

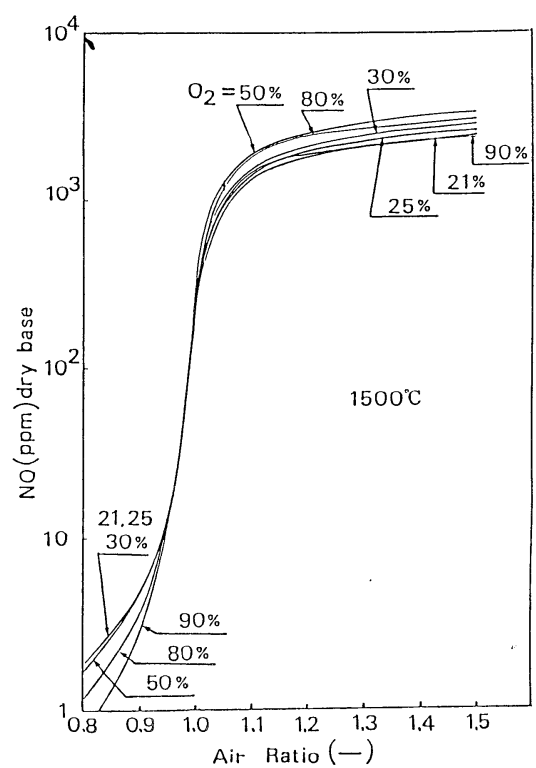

Fig. 5. Relation between enriched air and the amount of $\mathrm{NO}$ emitted equilibrium.

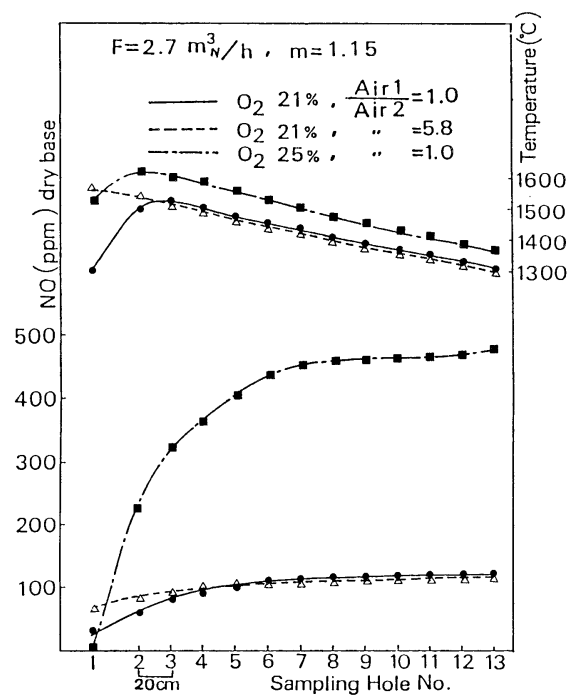

Fig. 6. NO concentration alon the axis in the horizontal kiln.

If these results are compared with calculated values for the equilibrium state, the maximum kiln temperatures recorded with enriched air and with ordinary air were $80.4 \%$ and $84.3 \%$ of the respective equilibrium values, but the measured NO concentrations at the exit of the kiln were $21 \%$ and $7.8 \%$ of the respective equilibrium values for the maximum recorded temperatures. As described above, as for the NO concentration, the measured and the calculated values differed markedly. This was caused by slow reaction rate of NO generation. In this way, the ratio of the 
measured value to the calculated value could give good information relating to reaction rate. Thus, when enriched air was used in place of ordinary air, the kiln temperature attained a slightly lower percentage of the adiabatic flame temperature, but the concentration of NO substantially increased relative to its equilibrium value. These results are attributed to the increase in the partial pressure of oxygen, which increased the rate of the NO generation reaction, and to the decrease in the combustion gas flow rate, which increased the residence time of the combustion gas in the kiln.

\section{3 The effect of oxygen enrichment on the} concentration and distribution of $\mathrm{NO}$ in a vertical high temperature kiln equipped with a diffusion burner

The value of the combustion parameters, i. e., fuel consumption and air ratio using ordinary air and enriched air, are shown in Fig. 7. The variation with time of the temperature at the center point of the kiln ( $25 \mathrm{~cm}$ from the ceiling), the concentration of $\mathrm{NO}$ at the same point and in the exhaust gas discharged from the outlet of the heat exchanger under identical conditions are shown in Fig. 8.

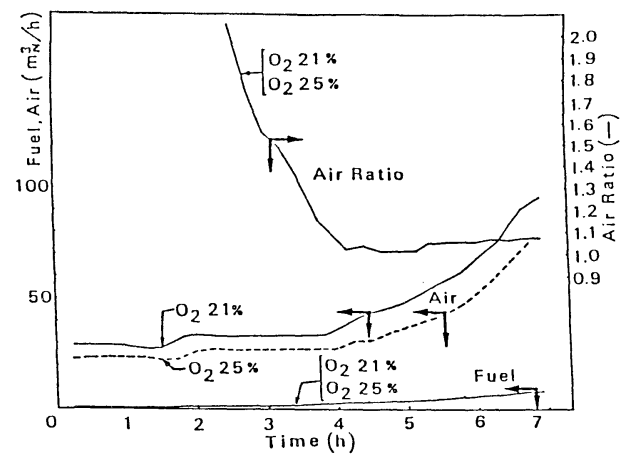

Fig. 7. Change in combustion parameters with time.

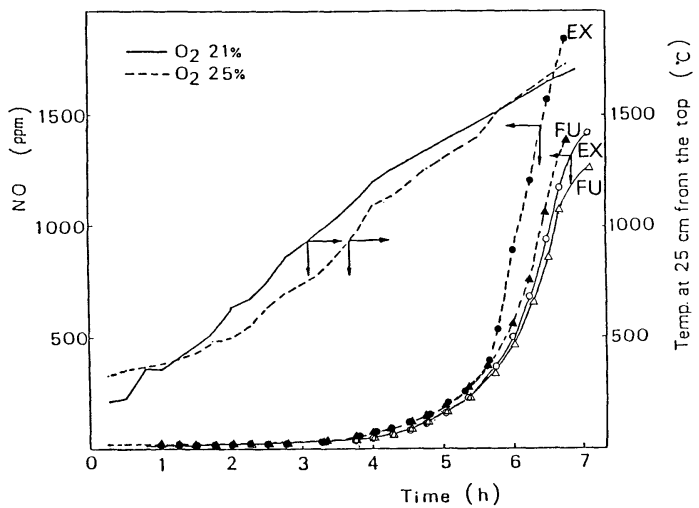

Fig. 8. Variation of temperature and NO concentration with time at center of kiln $(F U)$ and at outlet of heat exchanger (EX).
Regardless of the fact that the same fuel consumption curve and the same air ratio curve were followed in both cases, it may be seen from the temperature curve that until the temperature at the center of the furnace reached $1500^{\circ} \mathrm{C}$, the temperature at any given time was lower when enriched air was used in place of ordinary air. Some discrepancy is inevitable due to the difficulty in exactly reproducing the combustion conditions. Further, when using oxygen-enriched air, the flame becomes shorter as the combustion rate increases. Thus, the measured temperature in the case of oxygen-enriched air considered to be in fact lower than that in the case of ordinary air. In the low temperature range the higher oxygen concentration exerted no significant effect on the NO concentration. However, once the kiln temperature rose above $1500^{\circ} \mathrm{C}$, the $\mathrm{NO}$ concentration from oxygen-enriched combustion drastically increased. At high temperatures the NO concentration at the outlet of the heat exchanger was higher than at the center of the kiln. This result indicated the influence of the residence time of the combustion gas in the high temperature kiln on NO generation.

Figure 9 shows the effect of the temperature in the center of the kiln on the $\mathrm{NO} / \mathrm{NO}_{x}$ ratio $\left(\mathrm{NO}_{x}\right.$ means $\mathrm{NO}+\mathrm{NO}_{2}$ ) at the same point. Using either ordinary air or enriched air, a small amount of $\mathrm{NO}_{x}$ was generated at low temperatures with $\mathrm{NO}$ accounting for only a small percentage of the total $\mathrm{NO}_{x}$. However, as the temperature increased, $\mathrm{NO}$ accounted for a greater portion of the total $\mathrm{NO}_{x}$. As is well known, ${ }^{7)}$ about $95 \%$ of the total $\mathrm{NO}_{x}$ generated took the form of $\mathrm{NO}$ at temperatures greater than $1200^{\circ} \mathrm{C}$. It may be noted that at low temperatures, the $\mathrm{NO} / \mathrm{NO}_{x}$ ratio increased when

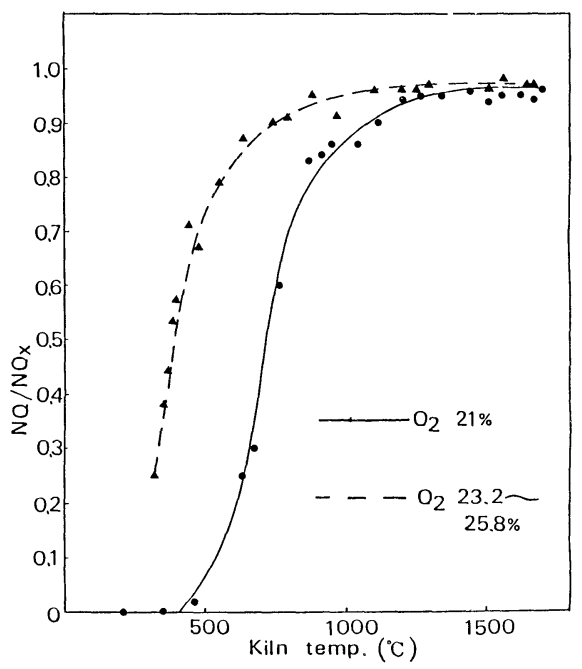

Fig. 9. Relation between $\mathrm{NO} / \mathrm{NO}_{x}$ ratio and temperature. 
enriched air was used in place of ordinary air. The reason for the $\mathrm{NO} / \mathrm{NO}_{x}$ ratio in the case of oxygen-enriched air higher than that in the case of ordinary air, is not presently clear. However, it has been reported that $\mathrm{NO}_{2}$ may be generated in a sampling tube by the oxidation of NO ${ }^{8)}$ Thus, it is thought that further study of current methods for both sampling and analysis would be desirable.

The temperature distribution and NO distribution inside the high temperature kiln at virtually steady state conditions are shown in Figs. 10 and 11, respectively. The air ratio was held constant at 1.11 in both cases, but in order to maintain approximately the same temperature at a prescribed point in the center of the kiln, it was necessary when using enriched air, to lower the fuel gas feed rate from 3.7 to $3.0 \mathrm{~m}^{3} / \mathrm{h}$. This reduction permitted an energy savings of $19 \%$, compared with the case of using only ordinary air.

In both cases the NO concentration gradually
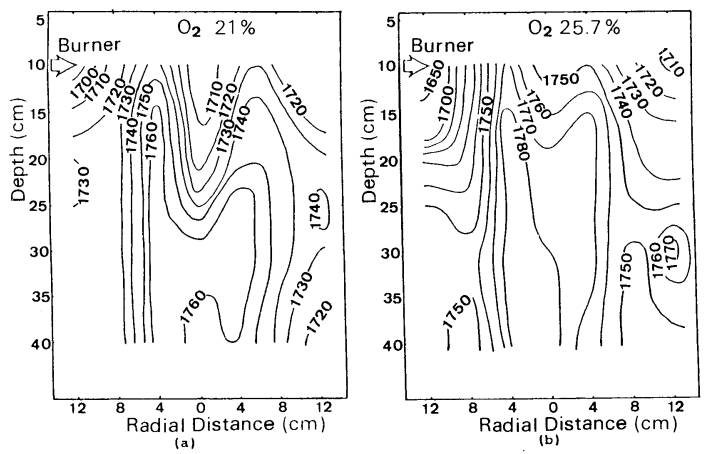

Fig. 10. Temperature distribution $\left({ }^{\circ} \mathrm{C}\right)$ in the high temperature kiln.

(a) fuel gas $=3.7 \mathrm{~m}^{3} / \mathrm{h}$, air $=45.0 \mathrm{~m}^{3} / \mathrm{h}$, air ratio $=1.11$

(b) fuel gas $=3.0 \mathrm{~m}^{3} / \mathrm{h}$, enriched air $\left(\mathrm{O}_{2}=25.7 \%\right)$ $=30.0 \mathrm{~m}^{3} / \mathrm{h}$, air ratio $=1.11$
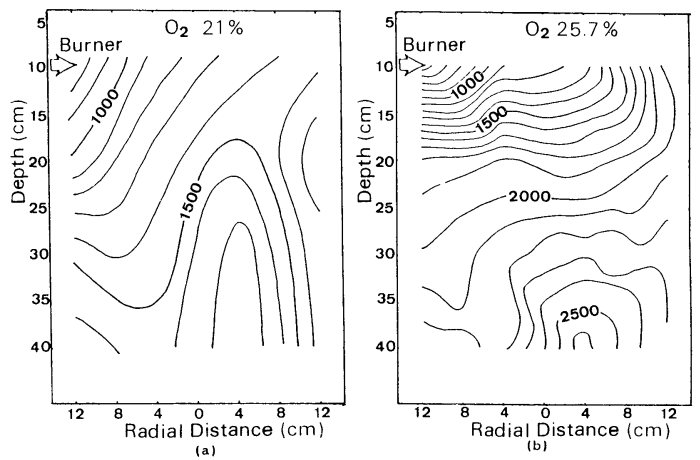

Fig. 11. NO distribution (ppm) in the high temperature kiln.
(a) fuel gas $=3.7 \mathrm{~m}^{3} / \mathrm{h}$, air $=45.0 \mathrm{~m}^{3} / \mathrm{h}$, air ratio $=1.11$
(b) fuel gas $=3.0 \mathrm{~m}^{3} / \mathrm{h}$, enriched air $\left(\mathrm{O}_{2}=25.7 \%\right)$
$=30.0 \mathrm{~m}^{3} / \mathrm{h}$, air ratio $=1.11$

increased from the position of the burner toward the bottom of the kiln. This result indicated that both the temperature and the residence time in the kiln influenced NO generation. The gradient of the NO concentration became steeper, i.e., the NO generation rate became higher when enriched air was used in place of ordinary air.

\section{Summary}

The following conclusions may be drawn from the previously mentioned experiments, in which two experimental kilns were used to investigate the combustion with oxygen-enriched air and the resulting generation of $\mathrm{NO}_{x}$.

If oxygen-enriched air is employed in place of ordinary air as combustion air, high temperatures may be attained more easily, but the concentration of NO in the combustion gas increased. Fixed temperature equilibrium calculations indicated that the concentration of $\mathrm{NO}$ in the combustion gas increased slightly with oxygen enrichment up to $50 \%$ oxygen, but the absolute amount of NO emitted actually declined. This decline may result in part from a decrease in the combustion gas flow rate due to the enrichment of the combustion air and in part from a decrease in the fuel gas flow rate since the fuel requirement to attain a given temperature is lower than that in the case of oxygen-enriched combustion.

However, in practice, the combustion reaction rate increase, when enriched air was used in place of ordinary air. As a result, the NO concentration increased significantly. In addition, the long residence time of the combustion gas in a high temperature region further contributed to an increase in the NO concentration.

Thus, the use of oxygen-enriched air has been shown to be a very effective means of obtaining extremely high temperatures in a combustion-type kiln, while providing significant energy savings.

\section{References}

1) K. H. Hemsath and F. J. Vereeke, Iron and Steel Eng., 52, 45-48 (1975).

2) B. M. Gibbs and A. Williams, J. Inst. Energy, 56, 74-83 (1983).

3) Y. Sakata, Kogyoukanetsu, 20, 35-45 (1983).

4) S. Asakawa and S. Shimizu, Nenryo oyobi Nensyo, 50, 338-44 (1983).

5) S. Shimizu, M. Wakamatsu, N. Takeuchi, G. Kurihara and S. Shimizu, Seramikkusu Ronbunshi, 96, 225-30 (1988).

6) J.H. Harker and D. A. Allen, J. Inst. Fuel (Now Energy), 42, 183-87 (1969).

7) For example, K. Otake and T. Fujiwara, "Combustion Engineering”, Corona Publishing Co., Ltd., Tokyo (1985) p. 184.

8) M. Hori, 20 th Symposium on Combustion (Preprint), 160-62 (1982). 